\title{
Vitamin C and Vitamin E in Prevention of Nonalcoholic Fatty Liver Disease (NAFLD) in Choline Deficient Diet Fed Rats
} Claudia PMS Oliveira*1, Luiz Carlos da Costa Gayotto ${ }^{2}$, Caroline Tatai ${ }^{1}$, Bianca Ishimoto Della Nina ${ }^{1}$, Emerson S Lima ${ }^{4}$, Dulcinéia SP Abdalla ${ }^{4}$, Fabio P Lopasso ${ }^{1}$, Francisco RM Laurindo ${ }^{3}$ and Flair José Carrilho ${ }^{1}$

\author{
Address: ${ }^{1}$ Department of Gastroenterology of Medical School of University of São Paulo (USP), São Paulo, Brazil, ${ }^{2}$ Department of Pathology \\ (LIM14) of Medical School of University of São Paulo (USP), São Paulo, Brazil, ${ }^{3}$ Departament of Heart Institute of Medical School of University \\ of São Paulo (USP), São Paulo, Brazil and ${ }^{4}$ Department of Clinical and Toxicological Analyses of School of Pharmaceutical Sciences of University \\ of São Paulo (USP), São Paulo, Brazil \\ Email: Claudia PMS Oliveira* - mauclaud@uol.com.br; Luiz Carlos da Costa Gayotto - luiz.gayotto@hcnet.usp.br; \\ Caroline Tatai - ctatai@yahoo.com; Bianca Ishimoto Della Nina - binina@hotmail.com; Emerson S Lima - dspa@usp.br; \\ Dulcinéia SP Abdalla - dspa@usp.br; Fabio P Lopasso - fabio_lopasso@uol.com.br; Francisco RM Laurindo - expfrancisco@incor.usp.br; \\ Flair José Carrilho - fjcarril@netpoint.com.br \\ * Corresponding author
}

This article is available from: http://www.nutritionj.com/content/2/I/9

(C) 2003 Oliveira et al; licensee BioMed Central Ltd. This is an Open Access article: verbatim copying and redistribution of this article are permitted in all media for any purpose, provided this notice is preserved along with the article's original URL.

\begin{abstract}
Aim: Oxidative stress has been implicated in the pathogenesis of Nonalcoholic Fatty Liver Disease (NAFLD). Vitamin C and vitamin E are known to react with reactive oxygen species (ROS) blocking the propagation of radical reactions in a wide range of oxidative stress situations. The potential therapeutic efficacy of antioxidants in NAFLD is unknown. The aim of this study was to evaluate the role of antioxidant drugs (vitamin $\mathrm{C}$ or vitamin $\mathrm{E}$ ) in its prevention.
\end{abstract}

Methods: Fatty liver disease was induced in Wistar rats by choline-deficient diet for four weeks. The rats were randomly assigned to receive vitamin $E(n=6)-(200 \mathrm{mg} /$ day $)$, vitamin $C(n=6)(30$ $\mathrm{mg} / \mathrm{Kg} /$ day) or vehicle orally.

Results: In the vehicle and vitamin E-treated rats, there were moderate macro and microvesicular fatty changes in periportal area without inflammatory infiltrate or fibrosis. Scharlach stain that used for a more precise identification of fatty change was strong positive. With vitamin $\mathrm{C}$, there was marked decrease in histological alterations. Essentially, there was no liver steatosis, only hepatocellular ballooning. Scharlach stain was negative. The lucigenin-enhanced luminescence was reduced with vitamin $C\left(1080 \pm 330 \mathrm{cpm} / \mathrm{mg} / \mathrm{min} \times 10^{3}\right)$ as compared to those Vitamin $E$ and control $\left(2247 \pm 790 ; 2020 \pm 407 \mathrm{cpm} / \mathrm{mg} / \mathrm{minx} / 0^{3}\right.$, respectively $)(p<0.05)$. Serum levels of aminotransferases were unaltered by vitamin $\mathrm{C}$ or vitamin $\mathrm{E}$.

Conclusions: I) Vitamin $C$ reduced oxidative stress and markedly inhibited the development of experimental liver steatosis induced by choline-deficient diet ; 2)Vitamin E neither prevented the development of fatty liver nor reduced the oxidative stress in this model. 


\section{Background}

There are evidences that fatty liver, the most common hepatocellular change found in liver biopsies in humans, can play a role in the pathogenesis of chronic liver disease $[1,2]$. Recently, some authors have considered that a more accurate denomination for this disease, which encloses the whole spectrum of fatty liver, nonalcoholic steatohepatitis (NASH) and eventually cirrhosis, is Nonalcoholic Fatty Liver Disease (NAFLD) [3,4].

Although several predisposing factors have been related to NAFLD, such as obesity, diabetes, jejunoileal bypass, dyslipidemia, drugs and parenteral nutrition, the pathogenesis of NAFLD and its progression to fibrosis and chronic liver disease are still unclear [4]. As a consequence, the current treatment is largely conservative Some hypotheses have been implicated in the pathogenesis of NAFLD, mainly liver injury mediated either by oxidative stress [5,6] or by endotoxins/cytokines [7-9]. and hyperinsulinemia [10] Oxidative stress is considered to play a central role in the pathogenesis of NAFLD because the increased production of ROS is known to cause lipid peroxidation, followed by activation of the inflammatory response, and of stellate cells, leading to fibrogenesis [1113]. Lipid peroxidation usually leads to the formation of peroxyl radicals, which are the central species of the peroxidation chain reaction. The aim of this study was to evaluate whether this process can be prevented by antioxidant drugs, vitamin C or vitamin E using an animal model where NAFLD was induced by a choline deficient diet

\section{Material and Methods \\ Animals and Study Groups}

This study was designed was in accordance with the Helsinki Declaration of 1975 and the Guidelines of Animal Experimentation from the School of Medicine of the University of São Paulo for the care and use of laboratory animals. Male Wistar rats, weighing 300 to $350 \mathrm{~g}$, were housed in cages with controlled light/dark cycle, receiving free water. Fatty liver was induced in Wistar rats by choline-deficient diet for four weeks $[14,15]$. Choline is an essencial nutrient for the export of triglycerides (VLDL) from the liver, and its privation causes fatty liver in the rat. The animals were distributed at random into three groups: vitamin $\mathrm{E}(\mathrm{n}=6)$ - fed a choline-deficient diet plus vita$\min \mathrm{E}(200 \mathrm{mg} /$ day $)$ orally; vitamin $\mathrm{C}(\mathrm{n}=6)$ - fed a choline-deficient diet plus vitamin $\mathrm{C}(30 \mathrm{mg} / \mathrm{Kg} /$ day $)$ orally; control $(n=6)$ - fed a choline-deficient diet plus vehicle orally. After four weeks the animals were sacrificed and samples of plasma and liver tissue were taken for biochemical, histological and oxidative stress analysis. The latter included the quantification of superoxide free radicals by chemiluminescence in liver tissue [16].

\section{Evaluation of hepatocellular injury}

Biochemical Analysis

Immediately after the sacrifice, plasma samples were drawn for the determination of hepatic enzymes (AST, ALT), cholesterol and triglycerides by standard methods.

\section{Histological Analysis}

fragments of liver tissue previously fixed in 10\% formaline saline were processed and submitted to hematoxilineosin-(HE) and Massons Trichrome stains. SCHARLACH Rs were used for a more precise identification of fatty change. Histological variables were semiquantitated from 0 to $4+$, including both macro-and microvesicular fatty change, the foci of necrosis, portal and perivenular fibrosis as well as the inflammatory infiltrate.

\section{Oxidative Stress Evaluation-Lucigenin-amplified chemiluminescence assays}

each fragment was immersed in Krebs-HEPES buffer (composition in mmol/L: $\mathrm{NaCl} \mathrm{118.3;} \mathrm{KCl} \mathrm{4.69;} \mathrm{CaCl} 2$ 1.87; MgSO4 1.20; KH2PO4 1.03; NaHCO3 25.0; Glucose 11.1 ; Na-HEPES 20.0 ) at $37^{\circ} \mathrm{C}$, strictly maintained at $\mathrm{pH} 7.40$, for at least 15 minutes. The hepatic fragments were rapidly transferred to a counter vial, under light protection, and immersed in $2.0 \mathrm{ml}$ of a solution of KrebsHEPES buffer and $0.50 \mathrm{mM}$ lucigenin (Sigma Chemicals). This lucigenin concentration was chosen because, instead of higher concentration ranges, it has been shown to reflect superoxide generation by tissues [16,17]. In each fragment, the light signals were counted for $10 \mathrm{~min}$ in a luminometer (Berthold Multi Biolumat). The counts were normalized for the dry weight of each fragment. The results were expressed as counts per min per mg. To validate the method, before and during the counts, some experiments were performed holding the hepatic fragments for 45 minutes in a solution of superoxide dismutase $(\mathrm{SOD})(100 \mathrm{U} / \mathrm{ml})$, a superoxide scavenger.

\section{Statistical Analysis}

quantitative data were expressed as mean \pm SD. Groups were compared using univariate analysis (ANOVA); $p$ value under 0.05 was considered to be significant.

\section{Results}

We observed moderate macro- and microvesicular fatty change in the periportal zone in control and vitamin Etreated rats (Figure 1), whereas in vitamin C-treated rats did not develop liver steatosis in this model (Figure 2). These aspects were validated by SCHARLACH Rs stain (Figure 3 and 4 ). In both test groups, necroinflammatory activity was minimal and no fibrosis was seen in any of the groups. Following choline-deficient diet, the levels of AST and triglycerides were increased to a similar extent in vehicle, vitamin $\mathrm{E}$ or vitamin $\mathrm{C}$-treated rats (Table 1). On the other hand, vitamin $\mathrm{C}$ prevented the rise of 


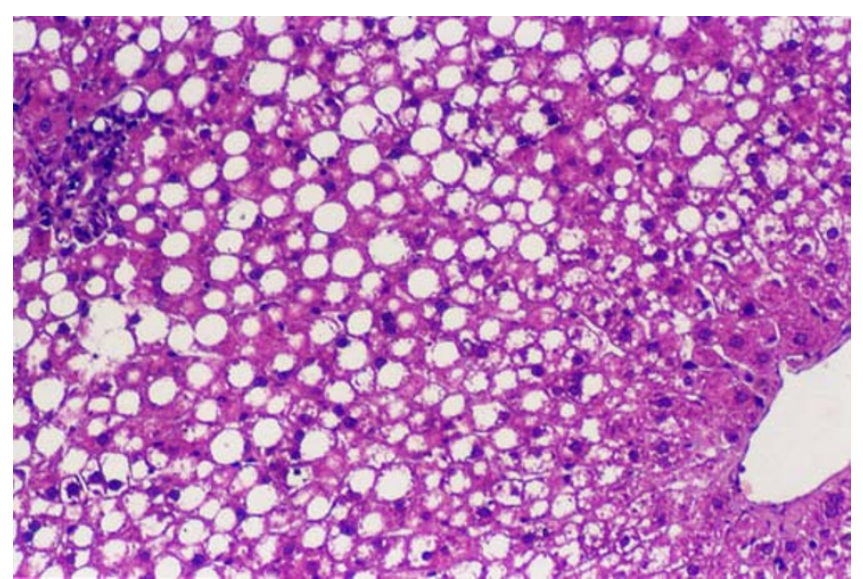

Figure I

Rats treated with vitamin E or vehicle-Macrovacuolar and microvaculoar fatty change involves mainly zone I of the hepatic acinus (Masson's Trichrome)

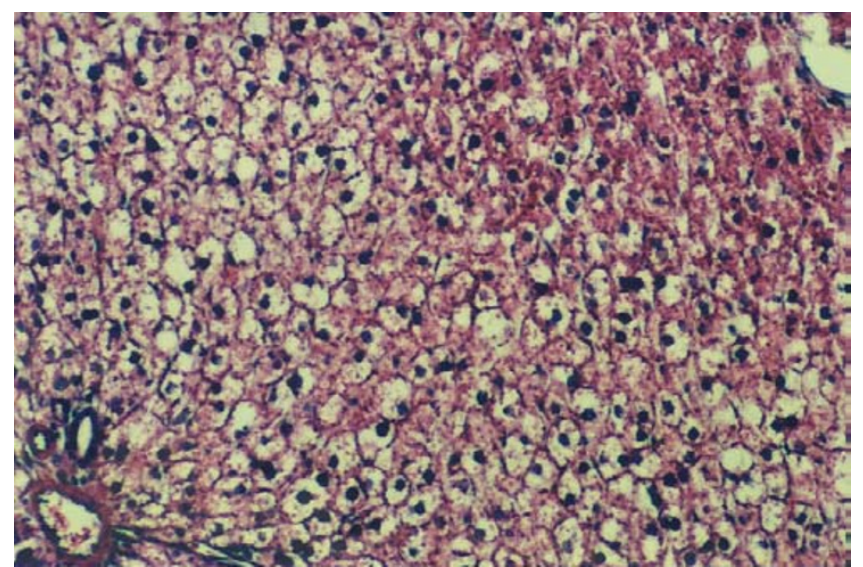

Figure 2

Rats treated with vitamin $C$ has normal hepatic lobule. Liver cells are slightly swolen with centraly placed nuclei. No fatty change is seen

luminescence values in the animals fed a choline-deficient diet plus vitamin $C\left(1080 \pm 330 \mathrm{cpm} / \mathrm{mg} / \mathrm{minx} 10^{3}\right)$ as compared to the animals fed a choline-deficient diet plus vitamin $\mathrm{E}$ or control $(2247 \pm 790 ; 2020 \pm 407 \mathrm{cpm} / \mathrm{mg} /$ $\left.\min x 10^{3}\right)(p<0.05)$ (Table 2).

\section{Discussion}

In this study, we managed to induce periportal macroand microvesicular steatosis in Wistar rats fed a cholinedeficient diet and evaluated the role of antioxidant drugs (vitamin $\mathrm{C}$ or vitamin $\mathrm{E}$ ) in the prevention of fatty liver.

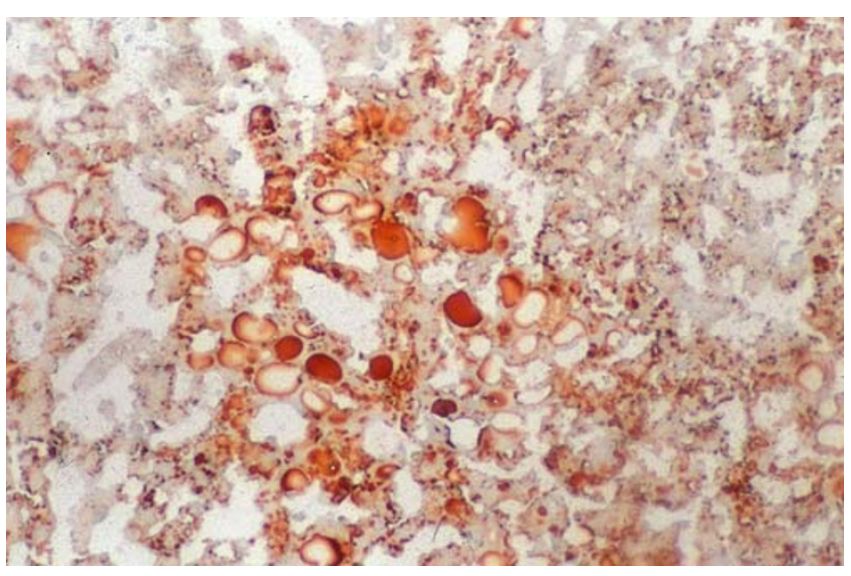

Figure 3

SCHARLACH Rs for fatty. The reaction is positive in control

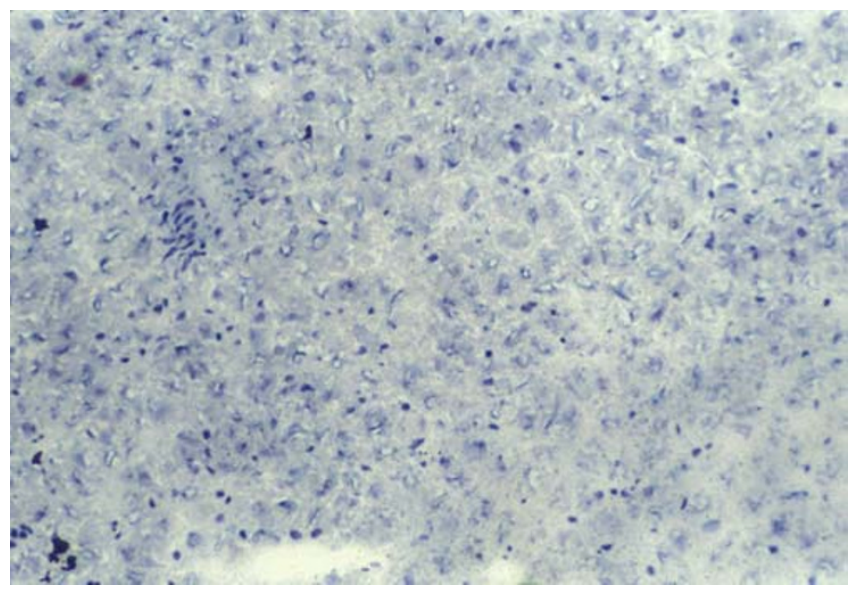

Figure 4

SCHARLACH Rs for fatty. The reaction is negative in vitamin $C$ treated-rats.

Our results showed a marked effect of vitamin $\mathrm{C}$ in the prevention of NAFLD in Wistar rats fed a choline-deficient diet.

A number of studies showed that parameter of oxidative stress are increase and levels of endogenous antioxidants such as vitamin $\mathrm{E}$ and glutathione (GSH) are decreased in NAFLD $[18,19]$. However, the use of antioxidants in the prevention of NAFLD is not established yet. The protective effect of vitamin C observed in our study is in line with the suggested role of oxidative stress in the pathogenesis of NAFLD. On the other hand, vitamin E another antioxi- 
Table I: Biochemical variables in the groups

\begin{tabular}{|c|c|c|c|c|c|}
\hline Group & $\mathrm{N}^{\circ}$ & AST (U/L) & $\mathrm{ALT}(\mathrm{U} / \mathrm{L})$ & Cholesterol (U/L) & Triglyceride (U/L) \\
\hline Control & 6 & $108 \pm 3$ & $40 \pm 1$ & $36 \pm 1$ & $88 \pm 3$ \\
\hline Vitamin E & 6 & $95 \pm 4$ & $37 \pm 8$ & $35 \pm 1$ & $70 \pm 1$ \\
\hline Vitamin C & 6 & $96 \pm 6$ & $28 \pm 8$ & $45 \pm 1$ & $104 \pm 6$ \\
\hline
\end{tabular}

Data expressed as mean \pm SD Normal values in U/L(AST = 10-34;ALT = 10-44; cholesterol e triglyceride $=$ until 45). Control - were fed a cholinedeficient diet for four weeks; Vitamin E - were fed a choline-deficient diet + vitamin E (200 mg/day) for four weeks; Vitamin C ( $n=6)-$ were fed a choline-deficient diet + vitamin $C(30 \mathrm{mg} / \mathrm{Kg} /$ day $)$ for four weeks.

Table 2: Lucigenin Amplified-Luminescence Values in Liver Tissue in The Groups

\begin{tabular}{lll}
\hline Group & $\mathrm{N}^{\circ}$ & Luminescence $\left(\mathrm{cpm} / \mathrm{mg} / \mathrm{min} \times 10^{3}\right)$ \\
\hline Control & 6 & $2247 \pm 790$ \\
Vitamin E & 6 & $2020 \pm 407$ \\
Vitamin C & 6 & $1080 \pm 330^{\dagger}$ \\
\hline
\end{tabular}

Data are expressed as mean $\pm \mathrm{SD} ; t p<0.05$ Vitamin $C \times$ control ; Luminescence data are expressed as cpm $\times 10^{3} / \mathrm{mg} \mathrm{dry} \mathrm{weight} / \mathrm{min}$. Control were fed a choline-deficient diet for four weeks; Vitamin $\mathrm{E}$ - were fed a choline-deficient diet + vitamin $\mathrm{E}(200 \mathrm{mg} /$ day) for four weeks; Vitamin $\mathrm{C}$ $(n=6)$ - were fed a choline-deficient diet + vitamin C (30 mg/Kg/day) for four weeks.

dant drug neither reduced oxidative stress and nor prevented the development of NAFLD in this study.

Choline-deficient diet is a classical general model of NAFLD. However, this model does not lead liver inflammation and therefore does not produce a typical histological picture of NASH [20]. Confirming this finding, Teramoto et al did not observe histological aspects of $\mathrm{NASH}$, but merely fatty change in rats fed 14, 28 and 42 days of a choline deficient diet [15]. Besides, in genetically obese mice in which spontaneous mutation (ob/ob) occurs, a second stimulus, such as the intraperitoneal injection of LPS (lipopolysacharide) is necessary to produce the histologic pattern of NASH [9]. Probably, this would parallel the human model in so far as a second stimulus such as toxins, alcohol or drugs would be needed to develop necrosis, inflammation and fibrosis in a fatty liver. Neverthless, once the pathogenesis of NASH and NAFLD share many common aspects, fatty change being their initial step, NAFLD would be appropriate to study the efficacy of antioxidant drugs.

This model indicated a strong effect in the vitamin C inhibit of fatty change. Vitamin C, a potent hydrosoluble antioxidant, surprisingly, inhibited the development of steatosis in the animals fed a choline-deficient diet and reduced the basal luminescence when it was administered orally daily. This protective mechanism of vitamin $\mathrm{C}$ could be suggested by antioxidant action because the observed reduction in the level of luminescence values reported here. Our group have demonstrated in previous studies [20] that the presence of steatosis showed some correspondence with the increase of superoxide anion generation in the animals fed a choline-deficient diet. Although some limitations of lucigenin-amplified chemiluminescence have been recently described, because lucigenin can undergo significant redox-cycling in the presence of reductases, generating itself artifactual superoxides [16], these findings were confirmed by the inhibition of luminescence by SOD administration. Neverthless, the oxidative hypothesis is by no means the only hypothesis that can be considered in the general context of the scope of use of antioxidants drugs in NAFLD. Vitamin E ( $\alpha$-tocopherol), a potent fat-soluble antioxidant with capacity to scavenge free radicals could not inhibit the development of steatosis in this model. Besides, in this study, vitamin E did not change the profile of biochemical and oxidative stress variables. Recently, Grattagliano et al showed in the same context, there is a depletion of endogenous antioxidants such as vitamin $\mathrm{E}$ and glutathione in liver tissue [18]. However, this does not imply that the administration of antioxidants would prevent fatty change. On the other hand, Lavine et al have demonstrated that vitamin E could reduce aminotransferases levels of obese children with NASH [21] and Hasegawa et al observed besides the reduction of aminotransferases, improvement of histological alterations. [22].

Moreover, curiously, vitamin $\mathrm{C}$, a potent hydrosoluble antioxidant, could inhibit the development of steatosis in this model. The real action of vitamin $\mathrm{C}$ in its prevention 
is a question because, although this drug have reduced the basal luminescence, the use of another antioxidant, vitamin E, could not prevent the development of steatosis. This fact can suggest that vitamin $\mathrm{C}$ could inhibit the development of steatosis by another mechanism. Some studies have demonstrated that ascorbic acid could reduce plasma levels of cholesterol and triglyceride demonstrating anti-atherogenic action [23].

In conclusion, our results suggest that NAFLD may be associated with oxidative stress and that the treatment with vitamin $\mathrm{C}$ may block the development of and NAFLD, while vitamin E may not. Future investigations are necessary to elucidate the role of ascorbic acid in NAFLD prevention.

\section{References}

I. Powell EE, Cooksley WG, Hanson R, Searle J, Halliday JW and Powell LW: The natural history of nonalcoholic steatohepatitis: a follow-up study of forty-two patients for up to 21 years. Hepatology 1990, II:74-80.

2. Lee RG: Nonalcoholic steatohepatitis: a study of $\mathbf{4 9}$ patients. Hum Pathol 1989, 20:594-598.

3. Matteoni CA, Younossi ZM, Gramlich TL and et al: Nonalcoholic fatty liver disease: a spectrum of clinical and pathological severity. Gastroenterology 1999, I 16:1413-1419.

4. Falck-Ytter Y, Younossi ZM, Marchesini G and McCullough AJ: Clinical features and Natural History of Nonalcoholic Steatosis Syndromes. Seminars in Liver Disease 200I, 2I(I): 17-26.

5. Chitturi $S$ and Farrell G: Etiopathogenesis of Nonalcoholic Steatohepatitis. Seminars in Liver Disease 200I, 2 I (I):27-4I.

6. Day CP and James OEW: Hepatic steatosis: innocent bystander ou guilty party. Hepatology 1998: I463-1466.

7. Tilg $\mathrm{H}$ and Diehl AM: Cytokines in Alcoholic and Nonalcoholic Steatohepatitis (Review Article). N Engl J Med 2000, 343(20): I 1467-1476.

8. Wigg AJ, Roberts-Thomson IC, Dymock RB, McCarthy PJ, Grose RH and Cummins AG: The role of small intestinal bacterial overgrowth, intestinal permeability, endotoxaemia, and tumour necrosis factor $\alpha$ in the pathogenesis of non-alcoholic steatohepatitis. Gut 200I, 48:206-2II.

9. Yang SQ, Lin HZ, Lane MD, Clemens M and Dieh AM: Obesity increases sensitivity to endotoxin liver injury: implications for the pathogenesis of steatohepatitis. Proc Natl Acad Sci USA 1997, 94:2557-2562.

10. Luyckx FH, Lefebvre PJ and Scheen AJ: Nonalcoholic steatohepatitis: association with obesity and insulin resistance, and influence of weight loss. Diabetes Metab 2000, 26:98-106.

II. Yang SQ, Zhu H, Li Y, Gabrielson K, Trush MA and Diehl AM: Mitochondrial Adaptations to Obesity-Related Oxidant Stress. Arch Biochem Biophysics 2000, 378(2):259-268.

12. Curzio M, Esterbauer $\mathrm{H}$ and Dianzani MU: Chemotactic activity of hydroxyalkenals on rat neutrophils. Int J Tiss Reac 1985, 7:137-I42

13. Lee KS, Buck M, Houglum K and Chojkier M: Activation of hepatic stellate cells by TGF alpha and collagen type $I$ is mediated by oxidative stress through c-myb expression. J Clin Invest 1995, 96:246I-2468.

14. Zeisel SH: Choline. In: Modern Nutrition in Health and Disease 8th edition. Edited by: Shils M, Olson JA, Shike M. Philadelphia, Pa: Lea \& Febiger; 1994:449-58.

15. Teramoto K, Bowers JL, Khettry U, Palombo JD and Clouse ME: A rat fatty liver transplant model. Transplantation 1993, 55:737-4I.

16. Brandes RP, Barton M, Philippens KMH, Schweitzer G and Mügge A: Endothelial-Derived Superoxide Anion In Pig Coronary Arteries; Evidence From Lucigenin Chemiluminescence and Histochemical Techniques. J Physiol 1997, 500:331-342.

17. Li Y, Zhu H, Kuppusamy P, Roubaud V, Zweier Jl and Trush MA: Validation of Lucigenin (Bis-N-Methylacridinium) as a Chemiluminescent Probe for Detecting Superoxide Anion Radical
Production by Enzimatic and Cellular Sources. J Biol Chem 1998, 273:2015-2023.

18. Grattagliano I, Vendemiale G, Caraceni P, Domenicalli M, Nardo B, Cavallari A, Trevisani F, Bernardi $M$ and Altomare E: Starvation impairs antioxidant defense in fatty livers of rats fed a choline-deficient diet. J Nutr 2000, I30(9):2 I3I-6.

19. Lettéron P, Fromenty B, Terris B, Degott $C$ and Pessayre D: Acute and chronic steatosis lead to in vivo lipid proxidation in mice. J Hepatol 1996, 24:200-208.

20. Oliveira CPMS, Gayotto LCC, Tatai C, Della Nina BI, Janiszewski M, Lima ES, Abdalla DSP, Lopasso FP, Laurindo FRM and Laudanna : Oxidative stress in the pathogenesis of nonalcoholic fatty liver disease, in rats fed with a choline-deficient diet. J Cell Mol Med 2002, 6(3):399-406.

21. Lavine JE: Vitamin E treatment of nonalcoholic steatohepatitis in children: A pilot study. J Pediatrics 2000, 136(6):734-738.

22. Hasegawa T: Plasma transforming growth factor- $\beta$, level and efficacy of $\alpha$-tocopherol in patients with non-alcoholic steatohepatitis: a pilot study. Alimentary Pharmacology and Therapeutics 2001, 15:1667-1672.

23. Okamoto $\mathrm{K}$ : Vitamin $\mathbf{C}$ intake and apolipoproteins in a healthy elderly Japanese population. Prev Med 2002, 34(3):364-9.
Publish with Bio Med Central and every scientist can read your work free of charge

"BioMed Central will be the most significant development for disseminating the results of biomedical research in our lifetime. "

Sir Paul Nurse, Cancer Research UK

Your research papers will be:

- available free of charge to the entire biomedical community

- peer reviewed and published immediately upon acceptance

- cited in PubMed and archived on PubMed Central

- yours - you keep the copyright

Submit your manuscript here:

http://www.biomedcentral.com/info/publishing_adv.asp
BiolMedcentral 